\title{
Advancing the Paris Agreement on Climate Change for Sustainable Development
}

\author{
Marie-Claire Cordonier Segger
}

\begin{abstract}
This article introduces and analyses the sustainable development dimensions of the Paris Agreement on climate change. After nearly seventeen years of deadlock, 197 Parties to the UN Framework Convention on Climate Change (UNFCCC) concluded a new international agreement at the 21st Conference of the Parties to the UNFCCC (COP21) in Paris on 12 December 2015. The Treaty aims to strengthen the global response to the threat of climate change in the context of sustainable development and efforts to eradicate poverty. This article reviews the provisions and principles of the accord, focusing on its potential contributions to sustainable development, and on the opportunities for domestic legal and institutional reform.
\end{abstract}

\section{Keywords}

Climate Change, Paris Agreement, United Nations Framework Convention on Climate Change, Sustainable Development, Human Rights

\section{Introduction}

After nearly seventeen years of deadlock, 197 Parties to the UN Framework Convention on Climate Change (UNFCCC) concluded a new international agreement on climate change at the $21^{\text {st }}$ Conference of the Parties to the UNFCCC (COP21) in Paris on 12 December 2015. The Treaty aims to strengthen the global response to the threat of climate change in the context of sustainable development and efforts to eradicate poverty. Parties seek to hold increases in global temperatures to well below $2^{\circ} \mathrm{C}$, pursuing efforts toward a $1.5^{\circ} \mathrm{C}$ limit; to increase adaptation to climate impacts and foster resilience; and to harness finance flows for low

* Senior Director, CISDL; Fellow, C-EENRG \& Affiliated Fellow, LCIL, University of Cambridge; Full Professor of Law, University of Waterloo, Canada; Executive Secretary, CLGI; and Senior Legal Advisor, UNFCCC COP22 Presidency. Special thanks and full acknowledgements are due to the GLGI, especially Ayman Cherkaoui, Christopher Campbell-Duruflé and Katherine Lofts, for their insightful and excellent research collaboration. 
greenhouse gas (GHG) emissions and climate-resilient development. The Paris Agreement sets a 'high ambition' framework for climate mitigation, adaptation and finance commitments by countries, backed by measures for inter-governmental cooperation on loss and damage, forests and land management, technology development and transfer, education and capacity-building, with a fit-to-purpose framework of transparency, peer review, stocktaking and compliance support. Adopting a 'bottom up' approach, it builds on submissions of climate action plans to the UNFCCC by 188 countries up to December 2016, as Nationally Determined Contributions (NDCs) to the global response to climate change.

The climate Agreement is desperately needed, and only a first step. Climate change poses crucial challenges for sustainable development. The impacts of climate change threaten to undermine decades of social and economic development, to severely constrain efforts to protect the environment, and to affect a wide range of human rights, such as the rights to life, health, water, food, shelter, and an adequate standard of living. ${ }^{1}$ As the Intergovernmental Panel on Climate Change (IPCC) has noted, from 1880 to 2012 , average global temperatures increased by $0.85^{\circ} \mathrm{C}{ }^{2}$ Global emissions of carbon dioxide (CO2) have increased by almost 50 per cent since 1990, and emissions grew more quickly between 2000 and 2010 than in each of the three previous decades. ${ }^{3}$ Given current concentrations and on-going GHG emissions, it is likely that by the end of this century, the increase in global temperature will exceed $1.5^{\circ} \mathrm{C}$ compared to the $1850-1900$ period. ${ }^{4}$

1 UNCHR Res 7/23 (2008) UN Doc A/HRC/RES/7/23; UNGA Res 63/32 (26 November 2008) UN Doc A/RES/63/32; UNCHR Res 10/4 (2009) UN Doc A/HRC/RES/10/4; UNGA Res 63/281 (3 June 2009) UN Doc A/RES/63/281; Report of the Secretary-General 'Climate Change and its Possible Security Implications' (2009) UN Doc A/64/350; UNSC Presidential Statement (2011) UN Doc S/PRST/2011/15; UNCHR Res 18/22 (2011) UN Doc A/HRC/ $\mathrm{RES} / 18 / 22$.

2 Intergovernmental Panel on Climate Change, 'Climate Change 2014 Synthesis Report' (Summary for Policy Makers (SPM) Geneva 2015) <www.ipcc.ch/pdf/assessment-report/ar5/ syr/SYR_AR5_FINAL_full_wcover.pdf> accessed 3 June 2016, Section SPM 1.1, 2 (IPCC 2014 Report).

3 ibid.

4 It should be noted that a $1.5^{\circ} \mathrm{C}$ increase only constitutes the most certain scenario, with other outcomes carrying considerable percentages of likelihood as well. See IPCC 2014 Report (n 2) Section E1, 20 which shows that global surface temperature change for the end of the $21 \mathrm{st}$ century is likely to exceed $1.5^{\circ} \mathrm{C}$ relative to $1850-1900$ for all RCP scenarios except RCP2.6. It is likely to exceed $2^{\circ} \mathrm{C}$ for RCP6.0 and RCP8.5, and more likely than not to exceed $2^{\circ} \mathrm{C}$ for RCP4.5. 
Such changes have already led to serious repercussions and give rise to significant further risks worldwide. For example, food security is increasingly threatened. For each degree of temperature increase, grain yields decline by about 5 per cent. Oceans have warmed, with snow and ice diminishing and sea levels rising. The extent of Arctic sea ice has decreased since 1979, with 1.07 million $\mathrm{km}^{2}$ of ice loss every decade. ${ }^{5}$ From $1901-2010$, the global average sea level rose by $19 \mathrm{~cm}$ as ice melted and oceans expanded, with a further rise predicted of $24-30 \mathrm{~cm}$ by 2065 and $40-63 \mathrm{~cm}$ by $2100 .^{6}$ At the same time, studies comparing 88 recent forest 'die-offs' show that increases in drought and heat stress are fundamentally altering forests in many regions, with a rise in tree mortality associated with climate-induced stress, insect outbreaks and wildfire. ${ }^{7}$ Recent reports suggest that the costs of climate change adaptation will reach between USD 70 and USD 100 billion a year by $2050 .{ }^{8}$

Most effects of climate change will persist for many centuries even if emissions were halted immediately. Perhaps most troubling, current regulatory and financial regimes guiding development continue to privilege carbon-intensive, unsustainable options, rather than promoting sustainable development, and making finance flows consistent with a pathway towards low GHG and climate-resilient alternatives, as sought by the 2015 Paris Agreement. However, as this article argues, it is still possible, using a wide array of legal and institutional measures, to limit the increase in global mean temperature to well below $2^{\circ} \mathrm{C}$ above pre-industrial levels. Major regulatory, institutional, economic and technological transformations, if carried out promptly, offer the world a chance to limit dangerous consequences to below this threshold.

The UNFCCC was concluded in 1992 and is the central framework for global efforts to avoid the dangers of climate change. ${ }^{9}$ While the Treaty itself does not contain binding GHG emission limits or enforcement mechanisms, it does provide a framework for the negotiation of further protocols and instruments. The Kyoto

6 ibid.

7 Craig D Allen and others, 'A Global Overview of Drought and Heat-induced Tree Mortality Reveals Emerging Climate Change Risks for Forests' (2010) 259 Forest Ecology and Management 660.

8 Muyeye Chambwera and others, 'Economics of Adaptation' in Christopher B Field and others (eds), Climate Change 2014: Impacts, Adaptation, and Vulnerability. Part A: Global and Sectoral Aspects. Contribution of Working Group II to the Fifth Assessment Report of the Intergovernmental Panel on Climate Change (CUP 2014) 945, 959. into force 21 March 1994) 1771 UNTS 107 (UNFCCC). 
Protocol ${ }^{10}$ includes binding emissions reduction targets for Parties, and is based on the principle of common but differentiated responsibilities and respective capabilities (CBDRRC). ${ }^{11}$ The first commitment period under the Protocol ended in 2012, and a second commitment period, known as the Doha Amendment, runs to $2020 .{ }^{12}$ However, these efforts have fallen short of what is needed to mitigate and adapt to dangerous climate change. Indeed, only 74 countries had accepted binding targets under the second commitment period of the Kyoto Protocol by December 2016, and current projections for average global temperature rise by the end of the century place warming well above the $1.5^{\circ}-2^{\circ} \mathrm{C}$ limit necessary to avoid dangerous climate change.

Failure to achieve the action plan agreed in Bali at the 13th Conference of the Parties (COP) to the UNFCCC in 2007 made it impossible to reach a new agreement at COP15 in Copenhagen in 2009, and negotiations through a new process known as the Durban Platform for Enhanced Action (ADP) for a post2020 agreement were initiated at COP17 in Durban in 2011. From 25 February 2015, when the first draft text was made available, to the eighth part of the second session of the Ad Hoc Working Group on the ADP in Geneva on 8-15 February 2015, to the Bonn inter-sessional meeting (ADP 2-9), held from 1-11 June 2015, aspects were streamlined and consolidated. Further streamlined negotiating texts were released on 24 July 2015, 5 October 2015, and 6 November 2015, and intense negotiations continued throughout COP21 in Paris from 1-12 December 2015, for a Paris Agreement that was finally adopted by the COP21 on 12 December $2015 .{ }^{13}$ The Agreement entered rapidly into force upon ratification by 55 countries or more, representing 55 per cent of the world's emissions on 4 November 2016. In order to develop the initial 'rulebook' for the implementation of the Paris Agreement, an Ad Hoc Working Group on the Paris Agreement (APA) was established at the $44^{\text {th }}$ UNFCCC Subsidiary Bodies meeting in Bonn, Germany in May 2016. With over 114 ratifications by December 2016, the work of this APA proceeds alongside

10 Kyoto Protocol to the United Nations Framework Convention on Climate Change (adopted 11 December 1997, entered into force 16 February 2005) 2303 UNTS 148 (Kyoto Protocol).

11 Sandrine Maljean-Dubois and Pilar Moraga Sariego, 'Le Principe des Responsabilités Communes Mais Differenciées dans le Régime International du Climat' (2014) 55 Cahiers de Droit 83.

12 In accordance with arts 20 and 21 of the Kyoto Protocol, ratification by $75 \%$ of the Parties present and voting at the meeting is necessary for the Doha Amendment to come into force (144 Parties), which has not yet materialised.

13 Paris Agreement (adopted 12 December 2015) UN Doc FCCC/CP/2015/L.9/Rev.1. 
the First Conference of the Parties serving as the Meeting of the Parties to the Paris Agreement, known as the CMA, working to develop the 'Paris Rulebook' to implement the Agreement. The Treaty ${ }^{14}$ and its Adoption Decision ${ }^{15}$ aim to achieve climate mitigation, adaptation and finance through a series of cooperative frameworks and mechanisms, each of which establishes different legal rights and obligations for Parties, and explicitly makes provision for the needs of developing country Parties, especially the most vulnerable.

A focus on sustainable development is relevant for the leading high ambition countries, for emerging economies and for the most vulnerable countries of the world that are otherwise often excluded from international law-making. Indeed, in September 2016, Centre for International Sustainable Development Law (CISDL) legal research revealed that, out of 187 countries with intended Nationally Determined Contributions (iNDCs) published online by the UNFCCC registry, 156 countries explicitly prioritise an intention to undertake legal and institutional reforms. ${ }^{16}$ Further, 120 countries are calling on support from the international community in their iNDCs, with 51 stressing specifically the need for legal and institutional capacity-building. ${ }^{17}$ Building on the work of the Climate Law and Governance Initiative, ${ }^{18}$ this article, to be followed by a series of legal working papers and a new edited volume for Cambridge University Press as part of its Implementing Treaties on Sustainable Development Series, provides an overview of the Paris Agreement, discusses how the provisions of the Treaty reflect the principles

14 While a certain ambiguity may exist on this point, the Paris Agreement can be seen as a Treaty in the sense of art 2(a) of the Vienna Convention on the Law of Treaties (adopted May 1969, entered into force January 1980) 1155 UNTS 331. One indication is the need for ratification for its entry into force. It is a Treaty under the UNFCCC, however.

15 Conference on the Adoption of the Paris Agreement (12 December 2015, opened for signature 21 April 2016) UN Doc FCCC/CP/2015/L.9/Rev.1.

16 Marie-Claire Cordonier Segger, Mirjam Reiner and Alexandra Scott, 'Countries Stress Importance of Legal and Institutional Reforms in their iNDCs' (Climate Law and Governance Initiative September 2016) $4<\mathrm{http} / / /$ www.climatelawgovernance.org/knowledge-centre.html> accessed 7 September 2016.

17 ibid 5.

18 Climate Law and Governance Initiative partners include CISDL and McGill University Faculty of Law, C-EENRG and LCIL at University of Cambridge, IREDIES of La Sorbonne/Pantheon Faculty of Law in Paris, GEM at Yale University and University of Toronto, CR2 at University of Chile Faculty of Law, Ateneo School of Governance, University of Zambia Faculty of Law, and CASELAP at the University of Nairobi Faculty of Law, among others, in collaboration with IDLO, UNDP, UNEP, CIFOR, ILA, and the IUCN World Commission for Environmental Law. For details, see <http://www.climatelawgovernance.org/> accessed 10 November 2016. 
of international law on sustainable development, and considers the challenges and opportunities that it presents for domestic legal reform for sustainable development.

\section{Overview of the Paris Agreement on Climate Change}

The Paris Agreement aims to strengthen the global response to the threat of climate change, in the context of sustainable development and efforts to eradicate poverty, by holding the increase in the global average temperature to 'well below $2{ }^{\circ} \mathrm{C}$ above pre-industrial levels' and pursuing efforts to limit the temperature increase to $1.5^{\circ} \mathrm{C}$; by increasing the ability to adapt to the adverse impacts of climate change as well as foster climate resilience and low GHG emissions development; and by making finance flows consistent with a pathway towards low GHG emissions and climate resilient development. ${ }^{19}$ The international regime developed in an interactional manner over decades, ${ }^{20}$ as countries sought to address climate challenges domestically while also struggling to find an appropriate international cooperative framework.

In essence, the Paris Agreement presents a core triangle of obligations:

(i) countries must take nationally determined, quantifiable and progressive action for climate mitigation and adaptation;

(ii) these actions are incentivised by changes in financial flows and related technology transfer, capacity-building, education and other cooperative measures; and

(iii) enforcement is achieved through transparency and reporting, peer review, periodic stocktaking, public participation and compliance mechanisms.

The Paris Agreement seeks to enhance implementation of the UNFCCC, which sets out its ultimate objective at Article 2 as being the 'stabilization of greenhouse gas concentrations in the atmosphere at a level that would prevent dangerous anthropogenic interference with the climate system (...) within a time frame sufficient to allow ecosystems to adapt naturally to climate change, to ensure that food production is not threatened and to enable economic development to proceed

19 Paris Agreement (n 13) art 2.

20 Jutta Brunee and Stephen J Toope, Legitimacy and Legality in International Law: An Interactional Account (CUP 2010). 
in a sustainable manner. ${ }^{21}$ Specifically, the Paris Agreement aims to implement the commitments in Article 4 UNFCCC in accordance with the principles reflected in Article 3 UNFCCC. ${ }^{22}$

Article 2 of the Paris Agreement further specifies that the agreement will be implemented to 'reflect equity and the principle of [CBDRRC], in the light of different national circumstances. 23 The legal obligations of developing countries under the Paris Agreement are thus variable in order to equitably reflect their historical, economic, and social circumstances in comparison with that of other states. Article 3 of the Paris Agreement underscores that all Parties will undertake and communicate ambitious efforts (as defined in Articles 4, 7, 9, 10, 11 and 13) to achieve the aim of the agreement through NDCs to the global response to climate change. In doing so, it recognises, the efforts of all Parties will progress over time, and there is a need to support developing country Parties for effective implementation.

The Paris Agreement aims to achieve climate mitigation, adaptation and finance through a series of cooperative frameworks and mechanisms, each of which establishes different legal rights and obligations for Parties, and explicitly makes provision for the needs of developing country Parties, especially the most vulnerable. These are intended to: (1) achieve NDCs to mitigation and adaptation, through (2) mobilisation of resources, (3) transparency, global stocktaking, review and facilitative dialogue, (4) a sustainable development mechanism and non-market approaches, (5) technology transfer, and (6) further implementation measures, such as capacity-building, education, and a compliance mechanism.

UNFCCC (n 9) (emphasis added); While there is an unequivocal link between the Paris Agreement and the UNFCCC, the Agreement remains silent on the actual nature of the relationship between the two documents. The Paris Agreement could be said to constitute a de facto Protocol under the UNFCCC but may also be characterised as a subsequent agreement. The latter option would give more room for an interpretation of the terms of the Paris Agreement independent of the meaning contained in the UNFCCC. See in that regard, Annalisa Savaresi, 'The Paris Agreement: A Rejoinder' (EJIL: Talk! 16 February 2016) <www. ejiltalk.org/the-paris-agreement-a-rejoinder/> accessed 12 June 2016.

The principles in art 3 UNFCCC (n 9) include intergenerational and intra-generational equity, common but differentiated responsibility, precaution, right to sustainable development, and non-discrimination. 


\subsection{Nationally Determined Contributions to Climate Mitigation and Adaptation}

One of the central aspects of the Paris Agreement is its 'bottom-up' approach. Paragraph 2(b) of Decision 1/CP.19 invited all Parties to communicate to the UNFCCC Secretariat NDCs for GHG emissions reductions. By COP22, 188 countries had submitted NDCs or iNDCs. Under Article 3 of the Paris Agreement, Parties commit that they 'shall prepare, communicate and maintain' successive NDCs and pursue domestic mitigation measures to achieve their commitments. Rather than setting out specific mitigation or adaptation targets for each country, the Paris Agreement commits Parties to nationally determine and transparently communicate their own objectives, to inform the international community of the progress in implementing and achieving them, and to participate in periodic global stocktaking to inform progressively higher ambition. Paragraph 13 of the Paris Agreement Adoption Decision recalls this invitation for Parties who have not done so already, for the pre-2020 period.

\subsection{GHG Emission Mitigation, Low Carbon GHG Emission Development Strategies and GHG Sinks and Reservoirs}

In Article 4 of the Paris Agreement, the Parties aim to reach global peaking of GHG emissions as soon as possible (recognising that this will take longer for developing country Parties) and to undertake rapid reductions thereafter in accordance with the best available science, so as to balance emissions by sources and removals by sinks in the second half of this century (Article 4.1). The notion of balancing emissions and removals can be understood as an objective of 'net zero' emissions, whereby any residual anthropogenic GHG emissions would be annulled by activities removing GHG from the atmosphere. Such a sequestration of GHG could occur through expansion of the activities of natural carbon sinks and reservoirs, such as forests or oceans, or through the deployment of carbon capture technologies. ${ }^{24}$

24 The utilisation of both carbon sinks (including afforestation) and carbon dioxide capture and storage (CCS) as well as bioenergy with carbon dioxide capture and storage (BECCS) feature prominently in several of the mitigation scenarios developed by the UNFCCC. This applies not only to overshoot scenarios (where the declared targets are exceeded for certain periods) but also to compensate for industries in which mitigation is more costly. However, there are 
The NDCs are communicated every five years (ie 2020, 2025, 2030, etc.). A Party may at any time adjust its existing NDC to enhance its level of ambition (Article 4.3, Article 4.11). These NDCs, once submitted by the government of a country, shall be recorded in a public registry maintained by the UNFCCC Secretariat. The information that must be included in the communication of NDCs, so as to facilitate clarity, transparency and understanding, is explained in paragraph 27 of the Adoption Decision (see also Decision 1/CP.20 paragraph 14). Furthermore, Parties shall account for their NDCs and, in accounting for GHG emissions and removals corresponding to the NDCs, Parties shall promote environmental integrity, transparency, accuracy, completeness, comparability and consistency, and avoid double-counting in accordance with guidance from Parties in the CMA (Article 4.13).

Among other sustainable development provisions, Article 4 of the Paris Agreement recognises that developed countries should take the lead by undertaking economy-wide absolute emission reduction targets, while developing countries should continue enhancing mitigation efforts, moving over time towards economy-wide targets (Article 4.4, see also Preamble paragraph 16). Support shall also be provided to developing country Parties for the implementation of mitigation efforts, recognising that enhanced support for developing country Parties will allow for higher ambition in their actions (Article 4.5, see also Articles 9, 10 and 11). The least developed countries (LDCs) and small island developing States (SIDS) may prepare strategies that reflect their special circumstances (Article 4.6). Parties shall take into consideration in the implementation of the Agreement the concerns of Parties with economies most affected by the impacts of response measures, particularly developing country Parties (Article 4.15). Further, over and above their NDCs, all Parties should strive to formulate and communicate Longterm Low-GHG Emission Development Strategies (LEDS), taking into account CBDRRC, in light of different national circumstances (Article 4.19).

In the Paris Agreement, Parties also agree that they should take action to conserve and enhance GHG sinks and reservoirs as described in UNFCCC Article 4.1(d), including forests. ${ }^{25}$ They are encouraged to take action to implement and support the existing framework as set out in related guidance and decisions already

also concerns associated with the deployment of CCS and BECCS. See IPCC 2014 Report (n 2) SPM 3.4, as well as Full IPCC Report, Box 3.3 'Carbon Dioxide Removal and Solar Radiation Management Geoengineering Technologies-Possible Roles, Options, Risks and Status' 89. 
agreed under the UNFCCC, in order to reduce emissions from deforestation and forest degradation (REDD+ framework), including through results-based payments. ${ }^{26}$ The role of conservation, sustainable management of forests and enhancement of forest carbon stocks in developing countries, but also alternative policy approaches such as joint mitigation and adaptation approaches for integral and sustainable management of forests, is emphasised, while the importance of incentivising non-carbon co-benefits is also reaffirmed (Article 5.2). These simple provisions arguably highlight and integrate many existing decisions and guidance for collaboration, including those established or strengthened in recent years.

\subsection{Adaptation Goal and Communications, and Efforts to Address Loss and Damage}

By virtue of Article 7, a global goal on adaptation is established, to enhance adaptive capacity, strengthen resilience and reduce vulnerability to climate change, with a view to contributing to sustainable development and ensuring an adequate adaptation response (Article 7.1). Each Party should submit and periodically update an Adaptation Communication, which may include a national adaptation plan, priorities, implementation and support needs, plans and actions, without creating additional burdens for developing country Parties (Article 7.10, Article 7.11). The Adaptation Communications shall be recorded in a public registry maintained by the UNFCCC Secretariat (Article 7.12).

Among sustainable development aspects of Article 7, the Treaty provides that adaptation is recognised as a global challenge faced by all with multiple dimensions, taking into account the urgent and immediate needs of those developing country Parties that are particularly vulnerable to the adverse effects of climate change (Article 7.1). The adaptation efforts of developing country Parties shall be recognised, in accordance with the modalities adopted by the first CMA meeting of the Paris Agreement Parties (Article 7.3), and Adaptation Committee

Ingrid Visseren-Hamakers and others, 'Trade-offs, Co-benefits and Safeguards: Current Debates on the Breadth of REDD+' (2012) 4 Current Opinion in Environmental Sustainability 646; Peter J Kanowski, Constance L McDermott and Benjamin W Cashore, 'Implementing REDD+: Lessons from Analysis of Forest Governance' (2011) 14 Environmental Science and Policy 111; Antonio G M La Viña and Alaya de Leon, 'Two Global Challenges, One Solution: International Cooperation to Combat Climate Change and Tropical Deforestation' (2014) CGD Climate and Forest Paper Series no 14 Working Paper 388. 
and the Least Developed Countries Expert Group (LEG) should be involved in this process (Adoption Decision paragraph 42). The Green Climate Fund is to expedite support for the least developed countries and other developing country Parties for the formulation of National Adaptation Plans (Adoption Decision paragraph 47).

Parties should strengthen their cooperation on enhancing action on adaptation, taking into account the Cancun Adaptation Framework (Article 7.7), and the global stocktake shall recognise and enhance these efforts, reviewing the adequacy and effectiveness of adaptation and support for it, and overall progress (Article 7.14, also Article 14). Continuous and enhanced international support shall be provided to developing country Parties for the implementation of commitments to enhance action on adaptation, to engage in adaptation planning, and to prepare, submit and periodically update their Adaptation Communications (Article 7.13, also Articles 7.7, 7.9, 7.10 and 7.11). The Paris Agreement recognises the importance of averting, minimising and addressing loss and damage associated with the adverse effects of climate change, including extreme weather events as well as slow onset events, specifically highlighting the importance of sustainable development in reducing risks of loss and damage (Article 8.1). The Paris Agreement also addresses the Warsaw International Mechanism for Loss and Damage associated with Climate Change Impacts, noting that this shall be subject to the authority and the guidance of the CMA, and that Parties should enhance understanding, action and support, on a cooperative and facilitative basis with respect to loss and damage associated with the adverse effects of climate change (Article 8.3, also Article 8.2).

Certain key priorities for cooperation and facilitation are identified in the Paris Agreement, such as early warning systems, emergency preparedness, slow onset events, events that may involve irreversible and permanent loss and damage, comprehensive risk assessment and management, risk insurance facilities, climate risk pooling and other insurance solutions, non-economic losses, as well as resilience of communities, livelihoods and ecosystems (Article 8.4). In the Treaty, Parties agree to ensure that the Warsaw International Mechanism (WIM) collaborates with existing bodies and expert groups, as well as relevant actors outside the Agreement (Article 8.5). They do not go further to define, deny or designate liability or compensation. In the Adoption Decision, while a new clearinghouse for risk transfer is established to serve as a repository for information on insurance and risk transfer to facilitate Parties' efforts to develop and implement comprehensive risk management strategies (Adoption Decision paragraph 49), it is simply stated that Article 8 of the Treaty does not involve or provide a basis for any liability or 
compensation (Adoption Decision paragraph 52). In essence, the Treaty neither confirms nor denies whether liability exists, or compensation should be provided, a stalemate in legal terms.

\subsection{Mobilisation and Direction of Climate Finance}

Under Article 9 of the Paris Agreement, developed country Parties shall provide financial resources to assist developing country Parties with respect to both mitigation and adaptation, in continuation of their existing UNFCCC obligations (Article 9.1), while other Parties are encouraged to provide financial support voluntarily (Article 9.2). At the same time, all Parties should increase their efforts in mobilising climate finance from a wide variety of sources, instruments and channels, noting the significant role of public funds, and taking into account the priorities and needs of developing country Parties, with the greater onus being on developed country Parties which shall take the lead (Article 9.3).

Prior to 2025, the COP shall set a new collective quantified goal from a floor of USD 100 billion per year, taking into account the needs and priorities of developing countries (Adoption Decision paragraph 54). Developed country Parties are strongly urged to scale up their level of financial support, with a concrete roadmap to achieve this goal by 2020 for mitigation and adaptation (significantly increasing adaptation finance) and to provide appropriate technology and capacitybuilding support (Adoption Decision paragraph 115). Developed country Parties shall biennially communicate indicative quantitative and qualitative information related to scaling up and mobilising financial resources, including as to the balance between adaptation and mitigation (as per Articles 9.1 and 9.3), as applicable. The financial mechanism of the UNFCCC serves as the mechanism for the Paris Agreement.

The provision of scaled-up financial resources should attempt to balance the provision of mitigation and adaptation resources and take into account countrydriven strategies and the priorities and needs of developing country Parties, especially those particularly vulnerable to climate change with significant capacity constraints, such as LDCs and SIDS, and considering the need for public and grantbased resources for adaptation (Article 9.4). The balance between mitigation and adaptation, and careful attention to opportunities for sustainable development, are key for global implementation of the Paris Agreement. 


\subsection{Transparency, Global Stocktaking and Peer Review}

By virtue of Article 13, in addition to reporting on mitigation and adaptation, Parties should also regularly provide Communications on a national inventory report of GHG emissions by sources and removals by sinks, prepared using good practice methodologies accepted by the IPCC (Article 13.7(a)), and the information necessary to track progress made in implementing and achieving NDCs (Article 13.7(b)). They should also provide information regarding climate change impacts and adaptation (Article 13.8).

Of particular interest for sustainable development, Article 13 mandates further transparency. For developing country Parties, information may be presented on financial, technological and capacity-building support needed and received under Article 9 on climate finance, Article 10 on technology transfer and Article 11 on capacity-building (Article 13.10). For developing country Parties, information may be presented on progress made on implementing capacity-building plans, policies, actions or measures to implement the Paris Agreement (Article 11.4). The LDCs and SIDS may submit the information required at their discretion (Adoption Decision paragraph 91).

As elements of pledge and review, the national inventory reports on GHG emissions by sources and removals by sinks, and the information for tracking progress, as well as the level of support, will be the object of a technical expert review and also of a multilateral consideration of progress (Article 13.11, Article 13.12, Article 13.13). The review process shall pay particular attention to the respective national capabilities and circumstances of developing country Parties. Support shall be provided to developing countries for the implementation of their transparency frameworks (Article 13.14), and for building capacity to participate in the process, on a continuous basis (Article 13.15). The 'enhanced transparency framework' shall build on the transparency arrangements under the UNFCCC (including monitoring, reporting and verification measures) and be implemented with common modalities, guidelines and procedures in a manner that is facilitative, non-intrusive, non-punitive, respectful of national sovereignty, and avoids placing undue burdens on Parties (Article 13.3). It shall supersede existing guidance (Adoption Decision paragraph 88).

As a further ambition/transparency measure, the Paris Agreement stipulates that its Meetings of the Parties shall periodically take stock of the Treaty's implementation, to assess collective progress towards achieving the Treaty's purpose and long-term goals-referred to as the 'global stocktake. Stocktaking 
will be comprehensive and facilitative, considering mitigation, adaptation and the means of implementation and support, in the light of equity and the best available science (Article 14.1). The first global stocktake is planned for 2023 and every five years thereafter (Article 14.2), and the outcome of the global stocktake shall inform Parties in updating and enhancing their actions and support, as well as in enhancing international cooperation for climate action (Article 14.3). The reviews, in essence, take place on many levels, engaging all aspects.

\subsection{Sustainable Development Market Mechanism and Non-Market Approaches}

Under Article 6, Parties may engage in 'international transfers of mitigation outcomes' towards their NDCs, through voluntary cooperation, to allow for 'higher ambition in their mitigation and adaptation actions' (Article 6.1). When using internationally transferred mitigation outcomes, Parties shall promote sustainable development and ensure environmental integrity and transparency, applying robust accounting and governance to avoid double-counting, consistent with guidance to be adopted by the CMA (Article 6.2). ${ }^{27}$

Further, a 'sustainable development mechanism' is established to promote mitigation of GHG emissions while fostering sustainable development; to incentivise and facilitate GHG mitigation by authorised public and private entities; to contribute to the reduction of emission levels in the host Party, which will benefit from mitigation activities resulting in emission reductions that can also be used by another Party to fulfil its NDC; and to deliver overall mitigation of global emissions (Article 6.4). It is established under the authority of the CMA, for use by the Parties on a voluntary basis, and is to be supervised by a body designated by the CMA (Article 6.4). Rules, modalities and procedures for its operation should be forthcoming (Article 6.7). The new mechanism might draw upon certain experience accumulated through the Clean Development Mechanism (CDM) under the Kyoto Protocol. However, a key question is how this mechanism will 
work in a world of NDCs, where developing countries (as potential hosts) also have agreed baselines and/or reference levels.

Provisions of interest to vulnerable developing countries include a commitment that a share of proceeds from the mechanism shall be dedicated to cover administrative expenses and to assist developing country Parties particularly vulnerable to climate change to meet adaptation costs (Article 6.7). There is also recognition of the importance of non-market approaches, and the definition of a framework to promote them, including public and private sector participation and coordination across instruments and relevant institutional arrangements (Article 6.8 and 6.9). It is not enough, perhaps many would argue, but provides a platform to build on.

\subsection{Technology Mechanism}

The Technology Mechanism established under the UNFCCC shall also serve the Paris Agreement (Article 10.3). Parties recognise the importance of technology for the implementation of mitigation and adaptation actions under the Paris Agreement, and commit to strengthening cooperative action on technology development and transfer (Article 10.2). They also establish a framework to guide the operation of the Technology Mechanism (Article 10.4). Of interest for sustainable development, Parties agree to focus on collaborative approaches to research and development, and on facilitating access to technology, in particular for early stages of the technology cycle, for developing country Parties (Article 10.5). Support, including financial support, shall be provided to developing country Parties, including for strengthening cooperative action on technology development and transfer at different stages of the technology cycle.

\subsection{Further Measures for Implementation of the Agreement}

\subsubsection{Cooperation for Capacity-Building}

Capacity-building under the Paris Agreement, according to Article 11, should enhance the capacity and ability of developing country Parties to take effective climate action, particularly 'countries with the least capacity, such as the least developed countries, and those that are particularly vulnerable to the adverse 
effects of climate change' (Article 11.1). All countries should cooperate to achieve this, and there is a specific provision that developed country Parties should enhance support for capacity-building actions in developing country Parties (Article 11.3). Capacity-building should be country-driven, responsive to national needs, and foster country ownership of Parties, including at the national, subnational and local levels, in particular for developing country Parties (Article 11.2). In essence, an effective, iterative process is called for-one that is participatory, cross-cutting and gender-responsive (Article 11.2). Capacity-building should be guided by lessons learned, including those from previous activities under the UNFCCC. There will be regular communication by all Parties that support capacity-building about their actions and measures (including the capacity-building done under regional, bilateral and multilateral approaches). Capacity-building will not just assist with technical capacity for implementing adaptation and mitigation actions, the facilitation of technology development, dissemination and deployment, and access to climate finance, but it will also support education, training and public awareness, and the transparent, timely and accurate communication of information (Article 11.1, Article 11.4, see also Article 13.15).

The Paris Agreement calls for capacity-building activities to be enhanced through appropriate institutional arrangements, to be created in the APA, and followed up in the CMA (Article 11.5). The Paris Committee on Capacity-Building is also created, with the aim of addressing gaps and needs in implementing capacity-building in developing country Parties and further enhancing capacitybuilding efforts, including with regard to coherence and coordination in capacity-building activities under the Convention (Adoption Decision paragraph 72). Further, a Capacity-Building Initiative for Transparency is created by the Adoption Decision, in order to build institutional and technical capacity, both pre and post-2020. This initiative will support developing country Parties, upon request, in meeting enhanced transparency requirements as defined in Article 13 of the Agreement in a timely manner (Adoption Decision paragraph 85).

\subsubsection{Education and Public Awareness}

The Paris Agreement affirms that Parties shall cooperate in taking measures, as appropriate, to enhance climate change education, training, public awareness, public participation and public access to information, recognising the importance of these steps with respect to enhancing actions under the Agreement (Article 12). 


\subsubsection{Implementation and Compliance Mechanism}

A mechanism to facilitate implementation of the agreement and to promote compliance is established (Article 15.1). This mechanism is structured as an expert-based and facilitative committee, and operates on a transparent, nonadversarial, and non-punitive way, according to procedures to be defined by the first CMA. The Compliance Committee shall pay particular attention to the respective national capabilities and circumstances of Parties. The Committee shall consist of 12 members with recognised competence in relevant scientific, technical, socio-economic or legal fields, to be elected by the COP on the basis of equitable geographical representation, with two members each from the five regional groups of the United Nations and one member each from the SIDS and the LDCs, taking gender balance into account (Adoption Decision paragraph 103).

\subsubsection{Governance and Dispute Settlement}

The Paris Agreement adopts the UNFCCC Rules of Procedure and Secretariat (Article 16 and Article 17); its governance structure, including the subsidiary body for scientific and technological advice (UNFCCC Article 9) and the subsidiary body for implementation (UNFCCC Article 10), the arrangements for voting and observer participation (Article 18 and Article 19), and its dispute settlement mechanism (Article 24, see also UNFCCC Article 14). The Agreement opened for signature from 22 April 2016 to 21 April 2017, and thereafter for accession (Article 20.1). It entered into force 30 days after 55 Parties to the UNFCCC-accounting for at least 55 per cent of global GHG emissions-joined (Article 21.1), which was 4 November 2016, a significant achievement demonstrating very high political momentum.

\section{Sustainable Development Dimensions of the Paris Agreement}

\subsection{Sustainable Development as a Purpose of the Paris Agreement}

In 2015, through 'Transforming our World: The 2030 Agenda for Sustainable Development', the UN and its member States agreed on 17 Sustainable Development Goals (SDGs) for the world, identifying time-bound targets and implementation 
methods. ${ }^{28}$ Legal reviews reveal that these SDGs can be found in the object and purpose of many important international treaties. ${ }^{29}$ Achieving SDG 13 to take urgent action to combat climate change and its impacts will be implemented in part through the Paris Agreement. Indeed, SDG 13 itself acknowledges that the UNFCCC is the primary international, intergovernmental forum for negotiating the global response to climate change. Other SDGs, for instance, on energy, water, hunger, poverty, biodiversity and innovation, are also highly relevant to the Treaty's objectives.

While all Parties, including those with the least historical contributions to global emissions, begin to play a role in emissions reduction, they also benefit from new investment and collaboration for low GHG pathways for sustainable development and poverty eradication. As an important instrument in the climate regime, the Paris Agreement holds all the hallmarks of a sustainable development accord. $^{30}$

The Paris Agreement is predicated upon an expectation that, if NDCs can be shaped and supported by peer review and public awareness, new scientific data on risks, actual impacts, and greater political attention will lead to ever-higher ambition from all levels of governments, along with non-State actors in the private sector and civil society. Some hope that countries, perhaps in groups with higher ambition, can move towards setting and achieving absolute emissions reduction targets, diversified enhanced mitigation actions, or arrangements among donors and beneficiaries to address key sectors. The former would seek to bind Parties to attain net zero emissions levels over the long-term through a quantifiable standard. The latter would set higher ambition, whether or not remaining recalcitrant countries also accept such actions as obligatory.

29 See Marie-Claire Cordonier Segger and Elizabeth Mrema (eds), 'The Contribution of International Law, Policy and Governance to the Sustainable Development Goals' (Issue Briefs, CISDL-UNEP 2016) <http://cisdl.org/research-publications-events/legal-briefs-reportsworking-papers.html>.

30 Marie-Claire Cordonier Segger and Ashfaq Khalfan, Sustainable Development Law: Principles, Practices, and Prospects (OUP 2004); Christina Voigt, Sustainable Development as a Principle of International Law: Resolving Conflicts between Climate Measures and WTO Law (BRILL 2009). 


\subsection{Commitments to Sustainable Development in the Adoption Decision}

A commitment to sustainable development permeates the Paris Agreement and its Adoption Decision. Indeed, the Decision begins by welcoming UNGA Res 70/1 on the global SDGs, particularly Goal $13,{ }^{31}$ and acknowledging that climate change is a common concern of humankind. The Adoption Decision also recognises that, when taking action on climate change, States must respect, promote and consider their human rights obligations; the right to development; the rights of indigenous peoples, children and others in vulnerable situations; gender equality and empowerment; and inter-generational equity. It acknowledges the need to promote universal access to sustainable energy in developing countries, alongside the deployment of renewables, especially in Africa. Important sustainable development principles such as transparency and public participation, integration of environmental concerns and human rights into economic decision-making, good governance, precaution, inter-generational equity, CBDRRC, and sustainable use of natural resources such as energy, are reflected in the Preamble to the Adoption Decision. ${ }^{32}$

Operationally, the Adoption Decision also clarifies that the Subsidiary Body for Scientific and Technological Advice will undertake a work programme under the framework for non-market approaches to sustainable development referred to in Article 6 of the Paris Agreement (paragraph 40); invites all UN agencies and financial institutions to provide information on how their development assistance and climate finance programmes incorporate climate-proofing and climate resilience measures (paragraph 44); recognises the link between adequate and predictable financial resources and sustainable management of forests (paragraph $55)$; recognises the co-benefits of voluntary mitigation actions for adaptation, health and sustainable development (paragraph 109); recognises the importance of taking national sustainable development priorities into account in the existing technical examination process on mitigation (paragraph 110(a)) and encourages Parties to make effective use of the Climate Technology Centre and Network to obtain assistance to develop economically, environmentally and socially viable

31 SDG 13 requires 'urgent action to combat climate change and its impacts, acknowledging that the UNFCCC is the primary international, intergovernmental forum for negotiating the global response to climate change. See UNGA Res 70/1 (n 27) 14.

32 See John H Knox, 'Linking Human Rights and Climate Change at the United Nations' (2009) 33 Harv Envtl L Rev 477; John H Knox, 'Climate Change and Human Rights Law' (2009) 50 Va J Int'l L 163. 
project proposals in the high mitigation potential areas identified in the process (paragraph 110(d)), among other measures of note.

\subsection{Principles of Sustainable Development in the Paris Agreement and its Adoption Decision}

States and legal scholars have long sought to identify principles of international law on sustainable development. ${ }^{33}$ In 2002, the International Law Association's (ILA) Committee on the Legal Aspects of Sustainable Development, after ten years of study, drew the outcomes of these global policy discussions together in its New Delhi ILA Declaration on Principles of International Law relating to Sustainable Development as a Resolution of its $70^{\text {th }}$ Conference. ${ }^{34}$ The New Delhi Declaration notes that:

sustainable development is now widely accepted as a global objective and [...] the concept has been amply recognised in various international and national legal instruments, including treaty law and jurisprudence at international and national levels.

In the New Delhi Declaration, seven principles of international law are highlighted which characterise treaties related to sustainable development ${ }^{35}$ and are reflected in decisions of international courts and tribunals. ${ }^{36}$ The Declaration suggests that States

33 Marie-Claire Cordonier Segger, 'Significant Developments in Sustainable Development Law and Governance: A Proposal' (2004) 28 Natural Resources Forum 61; Marie-Claire Cordonier Segger and others, 'Prospects for Principles of International Sustainable Development Law after the WSSD: Common but Differentiated Responsibilities, Precaution and Participation' (2003) 12 RECIEL 54.

34 International Law Association, 'New Delhi Declaration on the Principles of International Law Related to Sustainable Development' Resolution 3/2002; Nico Schrijver and Friedl Weiss (eds), International Law and Sustainable Development: Principles and Practice (Martinus Nijhoff 2004) 1-152, 699-706; Cordonier Segger and Khalfan (n 30) 95-191; Duncan French, International Law and Policy of Sustainable Development (MUP 2005); See also 7 CISDL Legal Working Papers detailing the meaning, scope and existing status in international law of each proposed ILA New Delhi Declaration Principle, online: <http://cisdl.org/public/docs/new_ delhi_declaration.pdf $>$ accessed 12 June 2016.

35 Marie-Claire Cordonier Segger and C J Weeramantry (eds), Sustainable Justice: Reconciling Economic, Social and Environmental Law (Martinus Nijhoff 2005) 561-92; Cordonier Segger and Khalfan (n 30).

36 Marie-Claire Cordonier Segger with C J Weeramantry, Sustainable Development in International Courts and Tribunals (Routledge 2017) (forthcoming). 
respect the following principles: 1) sustainable use of natural resources whereby States have sovereign rights over their natural resources, and a corresponding duty not to cause, or allow, undue damage to the environment of other States in the use of these resources; 2) inter and intra-generational equity and the eradication of poverty; 3) common but differentiated responsibilities and respective capabilities; 4) the precautionary approach to human health, natural resources and ecosystems, transferring the burden of proving lack of significant harm from an undertaking to the proponent, in cases of scientific uncertainty; 5) public participation, backed by access to information and justice; 6) good governance, with measures to support rule of law, coherence and anti-corruption; and perhaps most telling, 7) integration and interrelationship of human rights and social, economic and environmental objectives.

As has been noted elsewhere, this last principle may sometimes be calledin short-hand-a 'principle of sustainable development', holding that States must take into account the environmental and social (including human rights) aspects of economic plans or projects, integrating related measures and costs, to promote more sustainable development. ${ }^{37}$

These non-exhaustive 'sustainable development principles' are gaining certain recognition by States and other actors in international law. Some are not yet recognised as binding rules of customary international law, and in some cases, they might never be. However, they are increasingly reflected and made operational in binding international treaties, forming part of international law and policy in the field of sustainable development. ${ }^{38}$ Indeed, each is reflected in the Paris Agreement in different ways:

\subsubsection{The duty of States to ensure sustainable use of natural resources}

In the Paris Agreement, atmospheric and carbon resources are framed as key resources to be managed in a sustainable manner, one which avoids dangerous climate change, as noted in the Treaty preamble and in the substantive sections on mitigation. For example, in Article 2, Parties recognise that limiting the temperature increase to $1.5^{\circ} \mathrm{C}$ above pre-industrial levels would significantly reduce the risks and impacts of climate change. Parties are encouraged to take 
action on sustainable management of forests as a key natural resource and carbon sink (Article 5, Adoption Decision paragraph 55), including through REDD+ and alternative policy frameworks such as joint mitigation and adaptation approaches for the integral and sustainable management of forests. The protection of ecosystems, biodiversity, and oceans is also prioritised in the Paris Agreement (Preamble paragraph 13), alongside the need to build the resilience of socioeconomic and ecological systems, including through sustainable management of natural resources (Article 7.9(e) on adaptation).

\subsubsection{The principle of equity and the eradication of poverty}

The notion of equity arises frequently in the Paris Agreement, as was posited prior to the conclusion of the Treaty by leading legal scholars. ${ }^{39}$ In the Preamble of the Treaty, there are two references to equity and intergenerational equity, which also appear in the Preamble of the Adoption Decision. In the operational provisions of the Paris Agreement, it is noted that Parties should protect the climate on the basis of equity and the principle of CBDRRC (Articles 2 and 4). The importance of efforts to eradicate poverty are also highlighted (Preamble paragraphs 8 and 9), in the statement of the general objective of the Agreement (Article 2), and in relation to cooperation to implement NDCs (Article 6).

3.3.3 The principle of common but differentiated responsibilities and respective capacities

The Paris Agreement will be implemented to reflect the principle of CBDRRC, in light of different national circumstances (Article2). Each Party's successive NDC will represent a progression beyond their earlier one, with its highest possible ambition, reflecting its CBDRR (Article 4.3). Each Party will also strive to formulate and communicate long-term low GHG development strategies, mindful of CBDRRC (Article 4.19, Preamble paragraph 3). The Paris Agreement, to reflect CBDRRC, also commits to the provision and the mobilisation of financial assistance (Articles 9.1-3), assistance in adaptation efforts (Article 7.7(d)), facilitation of technology transfer (Article 10.6), and capacity-building (Article 11.1-3). 
3.3.4 The principle of the precautionary approach to human health, natural resources and ecosystems

The Treaty recognises an urgent 'threat' of climate change (Preamble paragraph 4) and the need to strengthen global response to the threat of climate change and to significantly reduce the risks of climate change (Article 2.1). In essence, while references could be more explicit, the Paris Agreement and the UNFCCC are founded on the precautionary principle. In order to stabilise GHG concentrations in the atmosphere at a level that would prevent dangerous anthropogenic interference with the climate system and in order to allow ecosystems to adapt naturally to climate change, so as to ensure that food production is not threatened and to enable economic development to proceed in a sustainable manner, mitigation and adaptation actions must be taken even in the event of scientific uncertainty as to the exact contours of the challenge. As asserted in several places in the Paris Agreement, action on climate change should also be guided by the best available scientific knowledge (Preamble paragraph 4). While not detracting from the precautionary nature of the Agreement, the emphasis on continuing to advance scientific knowledge is recognised in the long-term goal (Article 4.1), in provisions on adaptation (Articles 7.5 and 7.7(c)), and in plans for the global stocktake (Article 14.1), with specific reference to the work of IPCC. Such 'best available scientific knowledge', however, evolves over time, and precaution is still required when the science is uncertain, under the Convention itself (Article 3.3, UNFCCC).

\subsubsection{The principle of public participation and access to information and justice}

As noted in the Adoption Decision (Paragraphs 83, 84 and 110), and in the Paris Agreement (Preamble para 14), public participation and access to information are crucial for global responses to climate change, and for the success of the framework established by the Paris Agreement itself. The importance of public participation is emphasised throughout the Paris Agreement, including in provisions on mitigation (Article 4), adaptation (Article 7) and on the Sustainable Development Mechanism and non-market approaches (Article 6), which aim to enhance public and private sector participation in the implementation of NDCs. Further, Parties shall enhance education, training, public awareness, public participation and public access to information, recognising their importance in enhancing actions under the Agreement (Article 12). In essence, the Treaty depends on public engagement, informed by the information that is made available through the 
national communications that are submitted to international registries, the global stocktake, the peer review, and other measures, to assist Parties progressively to intensify their contributions to mitigation, adaptation, finance and other aspects of the global response to climate change. There is an unprecedented recognition of the importance (for some) of 'climate justice' in taking action to address climate change, in the Preamble at paragraph 13. As explained in Sustainable Justice, climate change is the justice challenge of this century, both in terms of its causes, and who is disproportionately affected by its impacts. ${ }^{40}$ As explained during negotiations by the Mary Robinson Foundation for Climate Justice, the UN Rapporteur on Human Rights and the Environment Professor John Knox, and also by the International Bar Association, there is a need to 'ensure communities, individuals and governments have substantive legal and procedural rights relating to the enjoyment of a safe, clean, healthy and sustainable environment and the means to take or cause measures to be taken within their national legislative and judicial systems and, where necessary, at regional and international levels, to mitigate sources of climate change and provide for adaptation to its effects in a manner that respects human rights. ${ }^{41}$ Although 'access to justice' may not be expressly mentioned in the Agreement, Parties intended to access the same dispute settlement measures as the UNFCCC (Article 24).

\subsubsection{The principle of good governance}

Good governance is essential in the context of the Paris Agreement, particularly for the cooperative approaches that involve the use of internationally transferred mitigation outcomes towards NDCs. Indeed, transparency and robust accounting are required in the measurement of such outcomes (Article 6). In the establishment of the Capacity-Building Initiative for Transparency (Adoption Decision paragraph 74(a), (b) and (h)), Parties seek to build institutional and technical capacity with regard to the transparency requirements defined in Article 13 of the Paris Agreement (Articles 85-99). Further, they are committed to ensuring transparency of action and also support, including the provision of climate finance (Adoption Decision paragraph 93(c)) among other measures.

40 Cordonier Segger and Weeramantry, Sustainable Justice (n 35).

41 International Bar Association, Climate Change Justice and Human Rights Task Force 'Achieving Justice and Human Rights in an Era of Climate Disruption' (IBA 2014). 
3.3.7 The principle of integration and interrelationship, in relation to human rights and social, economic and environmental objectives

By recognising the far-reaching nature of climate change across environmental, social and economic domains, as well as the need to act in a timely and effective manner in order to prevent detrimental impacts, the principle of integration of environmental and social/human rights considerations into economic decision-making permeates the Paris Agreement. The integration of economic and environmental concerns is found in the reference to 'climate-resilient development' (Article 2.1(c)), and in the linking of economic growth and sustainable development in the context of technology transfers (Article 10.5). Integration is also apparent in the references to economic diversification and sustainable resource management in the context of adaptation (Article 7.9(e)), which also highlights the resilience of socio-economic and ecological systems, underlining the need for adaptation measures to integrate all three objectives. The Paris Agreement supports the integration of environmental considerations into economic and social development, while ensuring that climate change actions are economically viable and respect human rights, as noted in the Adoption Decision (Preamble paragraph 7) and in the Paris Agreement Preamble (paragraph 11). This principle is also reflected in references to safeguarding food security, as noted in the Paris Agreement (Preamble paragraph 9), and to respect for human rights, gender equality, indigenous rights, and the integrity of Mother Earth (Preamble paragraph 13).

\section{National Legal Priorities for Implementation of the Paris Agreement}

Key aspects of the Paris Agreement respond to international legal obligations and are very likely to require domestic legislation for effective implementation.

\subsection{Nationally Determined Contributions and Mitigation Mechanisms}

(i) Nationally Determined Contributions: Parties' NDCs represent the emissions reductions and other actions that each country will contribute to global efforts to respond to climate change. In order to make their contribution, participate in peer review, and engage in the global stocktake 
process, Parties can implement changes across various sectors of public policy to reduce GHG emissions, to support the development of sinks and reservoirs (including forests), and to institute processes for collection, compilation and verification of information. In many cases, this requires domestic legislation in sectors such as energy, forests, water, land and other natural resources; also transportation, agriculture, finance, industry, trade, construction; in addition to environment, health and waste management; as well as adaptation, disaster risk reduction, resilience and natural disaster response.

(ii) Mitigation Mechanisms: The Sustainable Development Mechanism (SDM) and REDD+ are examples of mitigation mechanisms included in the Paris Agreement. Such mechanisms may also require legislation to implementfor example, in bringing various sectors into harmony or clarifying land tenure in order to support the establishment of REDD+, or in guiding the mandates and operations of the designated national authorities for the SDM.

(iii) Incentives for Mitigation Technologies: Best practices may be leveraged to incentivise mitigation technologies, including in the areas of cap and trade, carbon taxes and hybrid systems, both within subnational jurisdictions, among subnational jurisdictions, and among countries. The removal of perverse subsidies and the implementation of incentives for the development of clean technologies may also be key.

\subsection{Adaptation, Resilience, Loss and Damage}

(i) Disaster Risk Reduction: Disaster Risk Reduction (DRR) planning at the national level can be integrated with climate adaptation planning, in line with the Sendai Framework for Disaster Risk Reduction, and related regulations.

(ii) Disaster Response/Internal Climate Migration and Displacement: In addition to DRR planning, a legal framework for disaster response may be needed to assist those who are impacted by both slow and rapid onset climate disasters, including those internally displaced by climate change.

(iii) Incentives for Adaptation Technologies: As with mitigation technologies, the development and implementation of adaptation technologies-for 
example, to prevent coastal erosion and flooding-can be incentivised domestically and internationally.

(iv) Legal Rules of Adaptation Funds: Adaptation funds such as the Adaptation Fund, the Global Environment Facility Trust Fund, the Green Climate Fund and others, may require clear legal rules governing transparency, accountability, and effectiveness, and incorporating safeguards for human rights, the environment and other priorities.

(v) Loss and Damage: Legal approaches to address loss and damage, including investment in early warning systems, pooling of risk and insurance mechanisms among other measures, can be explored and piloted, informing global efforts to implement the Warsaw Mechanism.

\subsection{Climate Finance}

(i) Laws Governing Finance: Climate finance benefits from predictability and sustainability. In addition, full transparency in the way that financial resources are used for mitigation and adaptation activities can be key. To this end, effective rules, institutions and systems are important for the transparency, accountability and effectiveness of climate finance.

(ii) Laws Governing Incentives, Including Subsidies: Certain agricultural and industrial subsidies-for example, in the areas of fossil fuels, GHG emissions-intensive energy, mining and transportation-may need to be eliminated, while new subsidies may be created, including for renewable energy and clean technology, at the national level in order to stimulate a shift towards sustainable practices and in accordance with international trade rules. ${ }^{42}$

Thomas Cottier, Olga Nartova and Sadeq Z Bigdeli (eds), International Trade Regulation and the Mitigation of Climate Change: World Trade Forum (CUP 2009); Thomas Cottier, Olga Nartova and Anirudh Shingal, 'The Potential of Tariff Policy for Climate Change Mitigation: Legal and Economic Analysis' (2014) 48 JWT 1007; Kateryna Holzer and Thomas Cottier, 'Addressing Climate Change under Preferential Trade Agreements: Towards Alignment of Carbon Standards under the Transatlantic Trade and Investment Partnership' (2015) 35 Global Environmental Change 514; Thomas Cottier, 'Renewable Energy and WTO Law: More Policy Space or Enhanced Disciplines?' (2014) 5 RELP 40. 
4.4 Transparency, Communication, Peer Review and Global Stocktake

(i) Monitoring, Reporting and Verification (MRV): Necessary elements of transparency, including collection of national communications and related data, and ensuring its public availability, are key for the successful implementation of the Paris Agreement, and may require new laws, institutions and guidelines or standards to be adopted at national levels and internationally.

(ii) Social and Environmental Impact Assessments: Laws relating to the requirements for social and environmental impact assessments may be required for actions relating to new projects and policies on agriculture, infrastructure, transportation, industry, energy and natural resources, vis-à-vis their potential climate-related impacts. Such rules may also be strengthened to apply to climate change mitigation and adaptation projects, for example, CDM or REDD+, in order to minimise any negative human rights, social and environmental effects.

\subsection{Human Rights and Equity}

(i) Respect for Human Rights: Following the Cancun Agreements, which recognised the importance of respecting human rights in all climate related actions, the Paris Agreement also contains several references to respect for human rights. Human rights considerations-arising from the effects of climate change itself, as well as from Parties' climate change response measures-shall be taken into account at the national level. At its latest session, the Human Rights Council reaffirmed the importance of respect for human rights in the efforts to address climate change, building on previous statements to the same effect. ${ }^{43}$ In addition, as observed by the Office of the United Nations High Commissioner for Human Rights, respect for the right to public participation and access to information are guaranteed 
under international human rights law and, along with other fundamental rights, are critical to the success of efforts to address climate change. ${ }^{44}$

(ii) Recognition of Indigenous Peoples' Rights, Including Free, Prior and Informed Consent (FPIC): Climate response measures can recognise the specific rights of Indigenous peoples, as affirmed in the UN Declaration on the Rights of Indigenous Peoples ${ }^{45}$ and other binding international human rights treaties. Indigenous peoples can be included in participatory processes relating to climate change. The principle of FPIC may also be applicable in climate-related projects that affect the lands of indigenous peoples, and the traditional knowledge of indigenous peoples and local communities can be key for climate actions at the domestic level.

(iii) Climate Justice: As the Office of the United Nations High Commissioner for Human Rights has noted, the 'effects of climate change will be felt most acutely by those segments of the population who are already in vulnerable situations due to factors such as poverty, gender, age, minority status, and disability. ${ }^{46}$ Parties can adopt new measures to mainstream consideration for the right to non-discrimination of historically vulnerable groups across their climate policies and climate-related legislation, and take the necessary affirmative actions to ensure that climate change harms and climate response measures do not impact on substantive equality.

(iv) Climate Disputes, Arbitration and Litigation Strategies: Alongside the new Agreement, and building on the Urgenda decision in the Dutch Courts and other current cases, ${ }^{47}$ as well as recent legal scholarship and advocacy for a Draft Climate Compensation Act at national and local levels in key

OHCHR (2009) UN Doc A/HRC/10/61 paras 78-79; See also OHCHR (2011) UN Doc A/HRC/19/34; See also Sumudu Atapattu, 'Climate Change, Human Rights and Forced Migration: Implications for International Law' (2009) 27 Wis Int'l LJ 607; Sumudu Atapattu, 'Global Climate Change: Can Human Rights (and Human Beings) Survive this Onslaught?' (2008) 20 Colo J Int Environ Law Policy 35. OHCHR (2009) UN Doc A/HRC/10/61 para 42.

Kai Purnhagen, 'Climate Law: Dutch Decision Raises Bar' (2015) 523 Nature 410; For discussion, see David Estrin, 'Limiting Dangerous Climate Change: The Critical Role of Citizen Suits and Domestic Courts-Despite the Paris Agreement' CIGI Paper Series 101 (CIGI 2016) <https:// www.cigionline.org/publications/limiting-dangerous-climate-change-critical-role-citizensuits-and-domestic-courts> accessed 26 September 2016; See also Climate Justice Programme (2016) <http://climatejustice.org.au> accessed 10 November 2016. 
jurisdictions, ${ }^{48}$ it is likely that climate-related litigation strategies will continue to be advanced. Legislation relating to liability, response action and compensation for loss and damage due to climate change-including with regards to health, property, infrastructure, and industry—may be needed at the domestic level, in addition to provisions for related issues such as climate-induced displacement and migration. The facilitation of access to justice to existing judicial mechanisms or the establishment of new claims processes or tribunals may be important, along with good governance assurances in compensation mechanisms. ${ }^{49}$

\section{The Paris Agreement in its International Legal Context}

The Parties have sought, in drafting the Agreement, to make it compatible with other relevant treaty obligations across international law on human rights, environment, trade, investment and finance, demonstrating synergies, and co-benefits for all three pillars of sustainable development.

\subsection{Human Rights Instruments}

Of relevance to the new Agreement are the obligations contained in the International Covenant on Economic, Social and Cultural Rights (ICESCR), the International Covenant on Civil and Political Rights (ICCPR), the Convention to Eliminate All Forms of Discrimination Against Women (CEDAW), the Convention on the Rights of the Child (CRC), amongst other international and regional human rights instruments. Among regional instruments, recognition of the rights to private and family life, for instance under the European Convention on Human Rights, and to the right to culture and right to property for indigenous people under the InterAmerican system of human rights, are particularly significant.

48 Andrew Gage and Margaretha Wewerinke, 'Taking Climate Justice into our own Hands: A Model Climate Compensation Act' (WCEL/VELA 2015).

49 See Sumudu Atapattu, 'Climate Change, Differentiated Responsibilities and State Responsibility: Devising Novel Legal Strategies for Damage Caused by Climate Change' in Benjamin J Richardson and others (eds), Climate Law and Developing Countries: Legal and Policy Challenges for The World Economy (EEP 2009) 37; Christina Voigt, 'State Responsibility for Climate Change Damages' (2008) 77 Nordic J Int'l L 1. 
The Paris Agreement, in its Preamble, calls for Parties to implement their obligations in a manner that ensures the full respect for human rights. In particular, after intensive discussions in Paris, Parties agreed in the Preamble to acknowledge that climate change is a common concern of humankind and to respect, promote and consider their respective obligations on human rights when taking action to address climate change. As such, Parties may need to implement new domestic legal and institutional reforms to ensure mitigation action sufficient to safeguard the substantive human rights enshrined in fundamental accords such as the ICESCR, the ICCPR, and the CRC. These include the right to life, adequate food, the highest attainable standard of health, adequate housing, and access to safe drinking water and sanitation. Procedural rights of key importance to climate change which are recognised in the Aarhus Convention also include access to information, public participation, and access to justice. ${ }^{50}$ Special attention can also be directed to gender equality and the full and effective participation of women; the recognition and respect for indigenous peoples' rights in all climate actions and decision-making and the recognition and protection of the rights of those displaced by climate change (climate migrants).

\subsection{Environmental Agreements}

A number of multilateral environmental agreements are relevant to the implementation of the Paris Agreement. Examples include treaties on water, such as the Ramsar Convention on Wetlands, the Helsinki Water Convention and the New York Watercourses Convention; treaties on biodiversity such as the Convention on Biological Diversity (CBD) with its Cartagena Protocol on Biosafety and Nagoya Protocol on Access and Benefit Sharing (ABS), which also touch on sustainable development matters, the Convention on International Trade in Endangered Species (CITES), and the Convention on Migratory Species (CMS); treaties on chemicals, such as the Stockholm Convention on Persistent Organic Pollutants (POPs), the Rotterdam Convention on the Prior Informed Consent Procedure for Certain Hazardous Chemicals and Pesticides (PICs), the Basel Convention on the Control of Transboundary Movements of Hazardous Wastes and their Disposal; 
and also treaties on air and atmosphere, such as the Vienna Convention and its Montreal Protocol on Substances that Deplete the Ozone Layer and the Convention on Long-Range Transboundary Air Pollution (CLRTAP).

To achieve synergies and co-benefits, the Paris Agreement may need to establish climate change mitigation ambition that is sufficient to ensure that Member States fulfil their undertakings under other instruments to protect natural environments and ecosystems. ${ }^{51}$ For example, mitigation ambition and procedures for the monitoring, reporting and verification of States' emissions reductions commitments can help to minimise environmental impacts, such as the loss of wetlands due to sea level rise, coral die-off due to warming sea temperature and ocean acidification, increases in drought and desertification, and biodiversity loss to the greatest extent possible, taking account of the precautionary principle. Further, the information gathered and best practices developed under different multilateral environmental agreements may assist in refining the rules and implementing the Paris Agreement.

\subsection{Economic Instruments}

Trade, investment and financial instruments can support action on climate change, including action on mitigation, adaptation, and clean technology. Parties are seeking ways to harness international economic law to foster more efficient responses to climate change, and sustainable low carbon development pathways through negotiations in the World Trade Organization under its international treaties (the WTO Agreements); particular provisions on the environment, human rights or climate change, including renewable energy, forests, and environmental goods and services in regional trade agreements (RTAs); initial awareness in international investment agreements (IIAs); cooperation in specialised instruments, such as the agreements establishing the International Energy Agency, the International Renewable Energy Agency (IRENA), and the Energy Charter Treaty; changes in the interpretation of the mandates of international financial institutions (IFIs) and other means. ${ }^{52}$

51 The objective of promoting 'synergies and coherence' between environmental treaties was explicitly affirmed in UNGA Res 66/288 (27 July 2012) UN Doc A/RES/66/288 para 79.

52 See also Antonio G M La Viña, Joanne C Dulce and Naderev Saño, 'National and Global Energy Governance: Issues, Linkages and Challenges in the Philippines' (2011) 2 Global Policy 80; Pilar Moraga (ed), Energía, Cambio Climático y Sustentabilidad: Una Mirada desde el Derecho (Thomson Reuters 2013). 
As one example, the WTO has undertaken efforts to reduce perverse subsidies and to promote trade in environmental goods and services, such as the launch of plurilateral 'green goods' negotiations. ${ }^{53}$ Other efforts by trading nations have resulted in new models of investment agreements and regional trade agreements that may seek to be mindful of green procurement schemes, emissions trading systems, carbon taxes and other GHG reduction mechanisms. Further, there are opportunities to promote renewable energy cooperation and other climatecompatible economic development objectives, among other climate and sustainable development measures, in a new generation of RTAs. Initial examples include the EU-Peru-Colombia, EU-South Korea, Canada-EU and Japan-Switzerland accords, though arguably a great deal more can be done to ensure that trade, investment and financial instruments foster rather than frustrate achievement of the world's SDGs. ${ }^{54}$

The various international treaties described above, but especially accords such as the UN Convention on the Law of the Sea (UNCLOS) and its Regional Seas Conventions, also integrated agreements on sustainable development, such as the UN Convention to Combat Desertification (UNCCD), and the International Treaty on Plant Genetic Resources for Food and Agriculture (ITPGRFA), will be very important in international efforts to support implementation of the Paris Agreement. In essence, while three dimensions of sustainable development are reflected in the new climate agreement, many other global, regional and bilateral instruments exist to address related challenges. For Parties' commitments to be effectively implemented to avoid dangerous climate change, intersections of these inter-actional regimes are practically inevitable.

See WTO, 'Azevêdo welcomes launch of plurilateral environmental goods negotiations' $<$ www. wto.org/english/news_e/news14_e/envir_08jul14_e.htm> accessed 6 June 2016. Fourteen WTO members launched plurilateral negotiations for an Environmental Goods Agreement on 8 July 2014 at the WTO. These members said the talks will promote green growth and sustainable development while providing impetus for the conclusion of the Doha Round.

54 Markus W Gehring and others, 'Climate Change and Sustainable Energy Measures in Regional Trade Agreements (RTAs)' ICTSD Global Platform on Climate Change, Trade and Sustainable Energy Issue Paper No 3 August 2013 <www.ictsd.org/downloads/2013/08/climate-changeand-sustainable-energy-measures-in-regional-trade-agreements-rtas.pdf $>$ accessed 12 June 2016; See also Marie-Claire Cordonier Segger, Markus Gehring and Andrew Newcombe (eds), Sustainable Development in World Investment Law (Kluwer Law International 2011); and Markus Gehring and Marie-Claire Cordonier Segger (eds), Sustainable Development in World Trade Law (Kluwer Law International 2005). 


\section{Conclusion}

Given available scientific findings, there can be no sustainable development if the worst-case scenarios for climate change are not averted. Compliance with the Paris Agreement, with due consideration of the applicable principles of international law, is crucial to achieve all global SDGs. ${ }^{55}$ In this article, key international and domestic law and governance issues raised in the Paris Agreement have been identified and discussed to assist Parties and key institutions in their preparations to implement new climate change commitments. The negotiation of the Paris Agreement occurred in an environment characterised by the emergence of new forms of international governance, and its eventual implementation will be influenced by this reality. The fragmentation of international law into increasingly specialised regimes; polycentricism and multi-level action in rule-making and implementation; experimentalism and revisability of legal obligations; increased participation of non-State actors; increased recourse to non-binding standards; among other influences, are reshaping the context for compliance, and indeed the evolution of international law itself. ${ }^{56}$ These developments have transformed and informed the roles and engagement of all the actors involved in the UNFCCC process, including State delegations, non-State observers from civil society, academia and the private sector among others, and intergovernmental organisations. Jurists, legal institutes and associations, law schools, judges' networks, decision-makers, advocates and other members of the law and governance community worldwide have long sought legal and institutional reforms on multiple levels, including international, regional, national and sub-national level, to facilitate, incentivise and mandate effective action on climate change. ${ }^{57}$ Indeed, the International Bar Association has

55 Marie-Claire Cordonier Segger and Elizabeth Mrema (eds), 'Contributions of International Law to Implementing the Sustainable Development Goals' (CISDL/UNEP 2016); See also Usha Natarajan and Kishan Khoday, 'Locating Nature: Making and Unmaking International Law' (2014) 27 LJIL 573.

56 See, eg, Kenneth W Abbott and Duncan Snidal, 'Strengthening International Regulation Through Transnational New Governance: Overcoming the Orchestration Deficit' (2009) Vand J Transnat'l L 501; Matthew Hoffmann, Climate Governance at the Crossroads: Experimenting with a Global Response after Kyoto (OUP 2011); Harriet Bulkeley and others, Transnational Climate Change Governance (CUP 2014). Christopher Campbell-Durufle is recognised and thanked for excellent insights on these points.

57 Kelly Levin and others, 'Overcoming the Tragedy of Super Wicked Problems: Constraining our Future Selves to Ameliorate Global Climate Change' (2012) 45 Policy Sciences 123. 
highlighted ' $[\mathrm{t}]$ he need for climate change justice is (...) apparent in the unequal geographic distribution of its environmental effects. ${ }^{58}$

As the ILA Climate Change Principles affirm, States have an obligation 'to employ due diligence efforts to mitigate climate change impacts' in the design of any social and economic development plan which may result in significant emissions of GHGs (paragraph 5). ${ }^{59}$ The ILA's Committee on International Law on Sustainable Development, and its follow-up Committee on International Law relating to Sustainable Natural Resources Management, are further working to illuminate the principles and good practices of international law which guide efforts in this field. ${ }^{60}$

After a series of international symposia and conferences, backed by independent research and analysis, a consortium of law faculties from leading universities, together with key research institutes, inter-governmental agencies, law associations, judges' networks, experts commissions and others, launched the inaugural Climate Law and Governance Day on 4 December 2015 at the Paris COP21, opening a special forum for informed dialogue between experts, practising jurists, and decision-makers. ${ }^{61}$

For effective responses to climate change under international law, interactional forms of international law-making under framework treaties are proving essential. ${ }^{62}$ Many countries plan to reform their laws and institutions across diverse economic, environmental and social sectors in order to respond to the challenges of climate mitigation, resilience, technology, finance and accountability. ${ }^{63}$ Indeed,

59 ILA, 'Legal Principles Relating to Climate Change' (n 50); See also Expert Group on Global Climate Obligations, 'Oslo Principles on Global Obligations to Reduce Climate Change' (n 50).

60 ILA, 'New Delhi Declaration of Principles of International Law Relating to Sustainable Development' (n 34). See also Committee on the Legal Principles Relating to Climate Change, 'International Law on Sustainable Development' (ILA 2012).

61 Report from Climate Law and Governance Day, La Sorbonne Faculty of Law, PantheonSorbonne University, Paris, 4 December 2015 (CISDL/LCIL/IREDIES/IDLO/CIFOR/UNEP/ UNDP Paris 2015); Report from Climate Law and Governance Official Side Event to the UNFCCC COP21 in Paris, 11 December 2014 (CISDL/NCCSD/ASOG, Paris 2015) <www. climatelawgovernance.org > accessed 1 October 2016.

62 Toope and Brunnee (n 29).

63 See, eg, Robert Kibugi, 'Mainstreaming Climate Change into Public Policy Functions: Legal Options to Reinforce Sustainable Development of Kenya' (2012) 8 Fla A \& M UL Rev 205; Robert Kibugi, 'Legal Options for Mainstreaming Climate Change Disaster Risk Reduction in Governance for Kenya, in K O H Kheng-Lian (ed), Adaptation to Climate Change, ASEAN and Comparative Experiences (WSPC 2015) 409; Jose Ramon T Villarin, Ma Antonia Y Loyzaga 
as noted above, 156 countries explicitly state their intention to undertake legal and institutional reforms, out of 187 countries with 'intended Nationally Determined Contributions' (iNDC) published online by the UNFCCC registry, and 51 stress specifically the need for legal and institutional capacity-building in order to achieve their iNDCs. ${ }^{64}$ There is a pressing need for innovative legal knowledge, expertise and capacity-building to address the climate law and governance issues signalled in this article, in order to ensure a strengthened agenda for the implementation of the Paris Agreement and the broader global SDGs.

As countries seek to implement the Paris Agreement, including through the presentation of new and more ambitious NDCs and the adoption of domestic laws designing their transition to a low carbon economy, a profound comprehension of sustainable development, its principles, and parameters will be essential. As recognised in the Agreement itself, new legal research, education, awareness, capacity-building and technical assistance, especially in LDCs and SIDS, but also in high per capita emission countries, will also be necessary to ensure the success of the commitments undertaken in Paris, the avoidance of climate change's most dangerous consequences, and the transformation of the world's economies, societies and ecosystems towards sustainability.

and Antonio G M La Viña, 'In the Eye of the Perfect Storm: What the Philippines Should Do About Climate Change' (SCJ Professorial Lecture Working Paper July 2008) <http://ohm.ecce. admu.edu.ph/wiki/pub/Main/EandEMaterials/SCJ_doc.pdf> accessed 14 June 2016.

64 Cordonier Segger, Reiner and Scott, 'Countries stress importance of legal and institutional reforms in their iNDCs' (n 16). 